01

\title{
Неоствальдовское поведение дисперсных систем в процессах испарения и кристаллизации капель водно-органических растворов
}

\author{
(ㄷ Е.Н. Федосеева, ${ }^{1}$ В.Б. Федосеев ${ }^{2,9}$ \\ Национальный исследовательский Нижегородский государственный университет им. Н.И. Лобачевского \\ (НИИ химии Нижегородского университета), \\ 603950 Нижний Новгород, Россия \\ ${ }^{2}$ Институт металлорганической химии им. Г.А. Разуваева РАН, \\ 603137 Нижний Новгород, Россия \\ ๑ e-mail: vbfedoseev@yandex.ru
}

Поступило в Редакцию 24 января 2019 г.

В окончательной редакции 24 сентября 2019 г.

Принято к публикации 18 декабря 2019 г.

Описаны эксперименты с водными растворами органических веществ, демонстрирующие неоствальдовское поведение, при котором устойчивость мелких капель при испарении и кристаллизации выше, чем крупных. Подобное поведение ранее описано только для водных растворов некоторых неорганических солей. Показано, что неоствальдовское поведение имеет общую с оствальдовским созреванием термодинамическую природу и должно наблюдаться в дисперсных системах сложного химического состава. Описаны особенности воспроизведения неоствальдовского поведения, связанные с поверхностной активностью органических веществ в водных растворах. Изученные закономерности могут быть использованы при получении растворов органических и биоорганических веществ с концентрацией, существенно превышающей их растворимость в обычных условиях, а также для формирования узких распределений по размерам в различных спрей-технологиях.

Ключевые слова: оствальдовское созревание, неоствальдовское поведение, ансамбль капель, фазовые превращения, размерный эффект.

DOI: $10.21883 /$ JTF.2020.06.49270.23-19

\section{Введение}

Растущий интерес к состоянию вещества и процессам, происходящим в малых объемах (каплях, порах, включениях), связан с развитием и внедрением в химической и фармацевтической промышленности спрей-технологий и технологии микро- и нанореакторов, основанных на особенностях фазовых и химических превращений в дисперсных системах [1-5]. Если в дисперсной системе присутствуют летучие и нелетучие компоненты, процессы ее эволюции сопровождаются непрерывным изменением концентрации раствора, размеров, температуры дисперсных частиц (капель) [6,7].

Некоторые кинетические особенности фазовых превращений в многокомпонентных дисперсных системах (ансамбле капель раствора) впервые описаны в [8-11]. Одной из них является неоствальдовское поведение (НП), при котором испарение мелких капель и кристаллизация в них происходят медленнее, чем в крупных. В $[8,9]$ описаны наблюдения НП в реальном времени для ансамблей сидячих капель водных растворов неорганических солей. В общем виде интерпретация НП предложена в [8], более простое обоснование можно связать с разнонаправленным действием процессов, описываемых уравнением Кельвина-Оствальда и законом Рауля [11]. Согласно первому, при уменьшении радиуса капли давление пара в ее окрестности должно возрас- тать, согласно второму, при испарении летучего компонента его концентрация и соответственно давление пара уменьшаются.

Известны результаты компьютерного моделирования и косвенные наблюдения, подтверждающие НП [12-15]. Предположение о протекании в твердых материалах при отжиге или старении процессов, „обратных“ оствальдовскому созреванию, высказано на основе анализа разделенных большим интервалом времени гистограмм распределения частиц по размерам. В [12] эффект демонстрируют кластеры Аu в водном растворе, в [13] микрокристаллы $\mathrm{NH}_{4} \mathrm{NO}_{3}$. В [14] зафиксировано, что на свежеприготовленных подложках из слюды мелкие капли воды испаряются медленнее, чем крупные. Похожие явления наблюдались при ионном облучении наночастиц [16,17]. Ингибирование оствальдовского созревания эмульсий гептан-вода обсуждалось в [18]. Численным моделированием продемонстрировано „обращенное“ оствальдовское созревание кластеров [19].

Неоспоримой демонстрацией НП являются визуальные микроскопические наблюдения в реальном времени $[8,9]$. Эти простые и доступные эксперименты хорошо воспроизводятся для водных растворов ряда неорганических солей $\left(\mathrm{NaCl}, \mathrm{KCl}, \mathrm{NaNO}_{3}, \mathrm{NH}_{4} \mathrm{Cl}\right.$ и др.).

Экспериментальное воспроизведение неоствальдовского поведения и других размерных эффектов, описанных в $[8,9,20]$, для органических и водно-органических 
смесей было одной из задач настоящего исследования. Первое сообщение о возможности НП водно-органических смесей сделано в сообщении [21].

Как и оствальдовское созревание, НП имеет термодинамическую природу и, казалось бы, должно столь же просто проявляться в водно-органических смесях. Однако поиск подходящих смесей и микроскопическое наблюдение НП для них осложнены поверхностной активностью органических соединений. Поверхностная активность меняет один из основных параметров процесса - поверхностную энергию дисперсной фазы, от которой зависит давление насыщенного пара или концентрация насыщенного раствора в окрестности капель или кристаллов. Кроме того, при испарении растворителя меняется краевой угол смачивания и соотношение между видимым радиусом капли и кривизной ее поверхности.

В большинстве описанных ниже экспериментов НП наблюдалось в открытой системе, в которой давление пара растворителя во внешней среде специально не контролировалось. В более сложных экспериментах контакт с внешней средой частично экранировался [11], либо рядом с ансамблем капель помещался резервуар с растворителем или раствором [10]. Это позволяет не только замедлить скорость испарения, ограничивая взаимодействие с внешней средой, но и наблюдать более сложную кинетику эволюции ансамбля капель. В таких условиях капли взаимодействуют, замедляя или ускоряя испарение соседей, либо растут, поглощая растворитель из окружающей среды (резервуара, регулирующего давление пара). В результате наблюдается как монотонное изменение размеров капель, так и долговременные, апериодические осциллирующие превращения раствор-кристалл в отдельных каплях $[10,11]$.

Единого термина, описывающего подобные процессы, нет. Предложены „reversed“ или ,inverse Ostwald ripening“ $[12,13,15-17,19]$, есть также образное „digestive Ostwald ripening“" [12]. Варианты „reversed“ или „inverse“ могут быть истолкованы как обращение направления процесса созревания дисперсной системы с удалением ее от некоторого состояния, описанного Оствальдом. Это несколько искажает физический смысл. Как в описанных случаях, так и при освальдовском созревании дисперсная система стремится к состоянию равновесия путем выравнивания химических потенциалов подвижных компонентов в разных фазах и частицах системы. Использование нового термина вызвано тем, что наблюдения существенно отличаются от привычной для материаловедов и физхимиков картины оствальдовского созревания. Чтобы показать, что это чисто визуальные отличия, нами используется термин „неоствальдовское поведение“. Необходимость в нем, скорее всего, отпадет, когда станет общепринятым понимание того, что это один из возможных вариантов оствальдовского созревания для многокомпонентных систем.

На основе наблюдений НП растворов неорганических веществ сделаны количественные оценки степени пере- сыщения ряда солей в пико- и фемтолитровых объемах раствора. Согласно этим оценкам, НП является признаком повышения растворимости. В органическом синтезе повышение растворимости малорастворимых реагентов позволяет сместить химическое и фазовое равновесие, меняя выход продуктов в зависимости от размеров нанореактора. Рост растворимости лекарственных форм повышает их биологическую доступность, что является одной из актуальных проблем фармацевтики.

Закономерности неоствальдовского поведения можно использовать для формирования узких распределений частиц по размерам в процессах типа spray pyrolysis, spray forming, spray drying и др.

\section{Экспериментальная часть}

Микроскопические наблюдения выполнялись с использованием микроскопов МБС-10 с камерой-окуляром DEM-200, Dino-Lite AM451 и Levenhuk D670T.

Предметное стекло с ансамблем капель помещалось либо непосредственно на предметный столик микроскопа, либо использовалась описанная в [11] методика. В последнем случае ансамбль капель находился на нижней поверхности предметного стекла над подвижным резервуаром с растворителем. Изменение концентрации раствора в резервуаре позволяет контролировать парциальное давление растворителя, регулируя скорость испарения капель, и частично или полностью изолировать ансамбль капель от внешней среды.

Для устранения теплового влияния осветителя использовалась подсветка на основе светодиодного источника света и зеркал. Использованы подложки из стекла и лавсана. Часть предметных стекол была обработана хлорсиланом для повышения гидрофобности. Для распыления растворов использован кнопочный распылитель. Наблюдения эволюции ансамбля капель в цифровом формате сохранялись как видеофайлы длительностью до $30 \mathrm{~min}$, либо как серии кадров.

При приготовлении растворов использовались реактивы квалификации х. ч.

Эксперименты проводились при комнатных условиях, специально влажность и температура не контролировались и менялись в пределах $25-45 \%$ и $20-24^{\circ} \mathrm{C}$ соответственно.

\section{Результаты наблюдений}

Основной задачей эксперимента было обнаружение НП для органических соединений разных классов с целью проверки предположения об общей природе этого явления без детального исследования условий, в которых оно реализуется. В тексте выборочно приведены кинограммы, демонстрирующие НП.

Наглядные и убедительные наблюдения НП получены для глицина. 

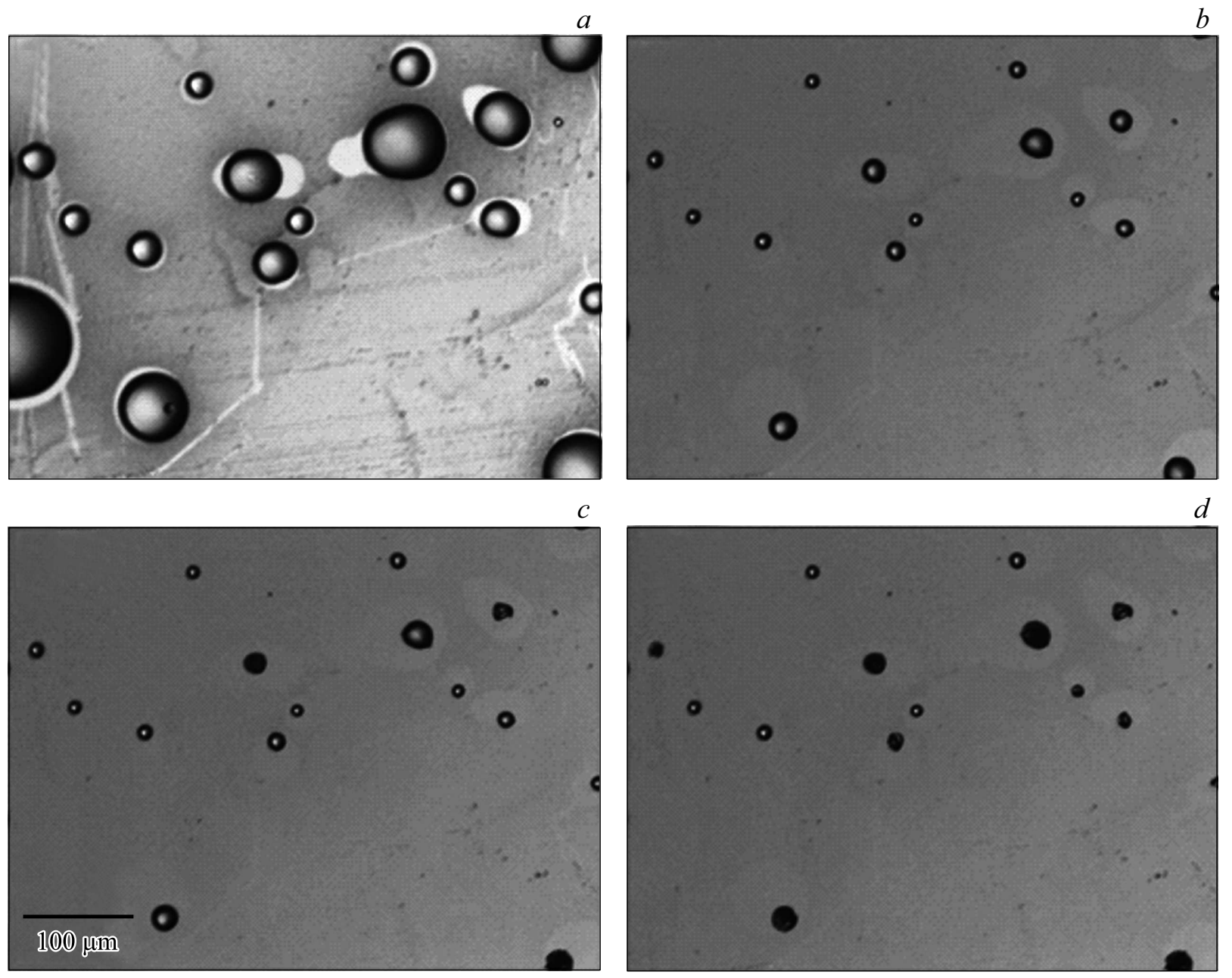

Рис. 1. Последовательность состояний ансамбля капель глицина через: $a-15, b-90, c-100, d-110$ s от начала съемки (на гидрофобизированном стекле, при $t=21.5^{\circ} \mathrm{C}$ и влажности $40 \%$ ).

Глицин обладает поверхностной активностью. На негидрофобизированном стекле капли раствора глицина растекаются с формированием уплощенной свободной поверхности с некруглой контактной площадкой. При кристаллизации в таких каплях образуются плоские дендриты. Последовательность кристаллизации капель соответствует НП - сначала в крупных, затем в мелких, но площадь контакта с подложкой при испарении не меняется, что затрудняет оценку радиуса кривизны и концентрации. Более отчетливо НП наблюдался на гидрофобизированных подложках, где капли раствора на всех стадиях испарения имеют близкую к сферической форму. В процессе испарения сильно уменьшается радиус капель, и кристаллизация начинается в крупных каплях (рис. 1). Кристаллы имеют форму сферолитов, сопоставимых по размеру с радиусом материнской капли.

Уротропин является представителем класса аминов. Его водные растворы демонстрировали более сложное поведение. Для раствора с концентрацией 3 mass.\% меньшие по размеру капли уменьшались в размерах много быстрее крупных, при этом не кристаллизуясь. Затем уменьшался радиус больших капель, после чего наблюдалась практически одновременная кристаллизация всего ансамбля капель. Для более концентрированного раствора (50 mass.\%) зависимость скорости испарения капель была неоднозначной. После кристаллизации большей части ансамбля капель на подложке рядом с кристаллами длительное время сосуществовали как крупные, так и самые мелкие капли раствора (рис. 2).

Раствор уротропина в этиловом спирте $(2.5 \%$ в $96 \%$ спирте) на подложках из лавсана и стекла тоже демонстрирует неоднозначное поведение. Уротропин малорастворим в этаноле $\left(2.89 \mathrm{~g}\right.$ на $100 \mathrm{~g}$ при $\left.20^{\circ} \mathrm{C}\right)$, концентрация его в исходном растворе была близка к насыщенной. Наблюдения за поведением капель осложнялись неконтролируемым растеканием исходных капель, поскольку спирт хорошо смачивает материал подложек. Тем не менее в ряде экспериментов удалось зафиксировать эффект НП, когда при испарении первыми кристаллизуются большие капли. В этом случае происходит образование дендритообразных кристаллов в объеме капли (рис. 3). 

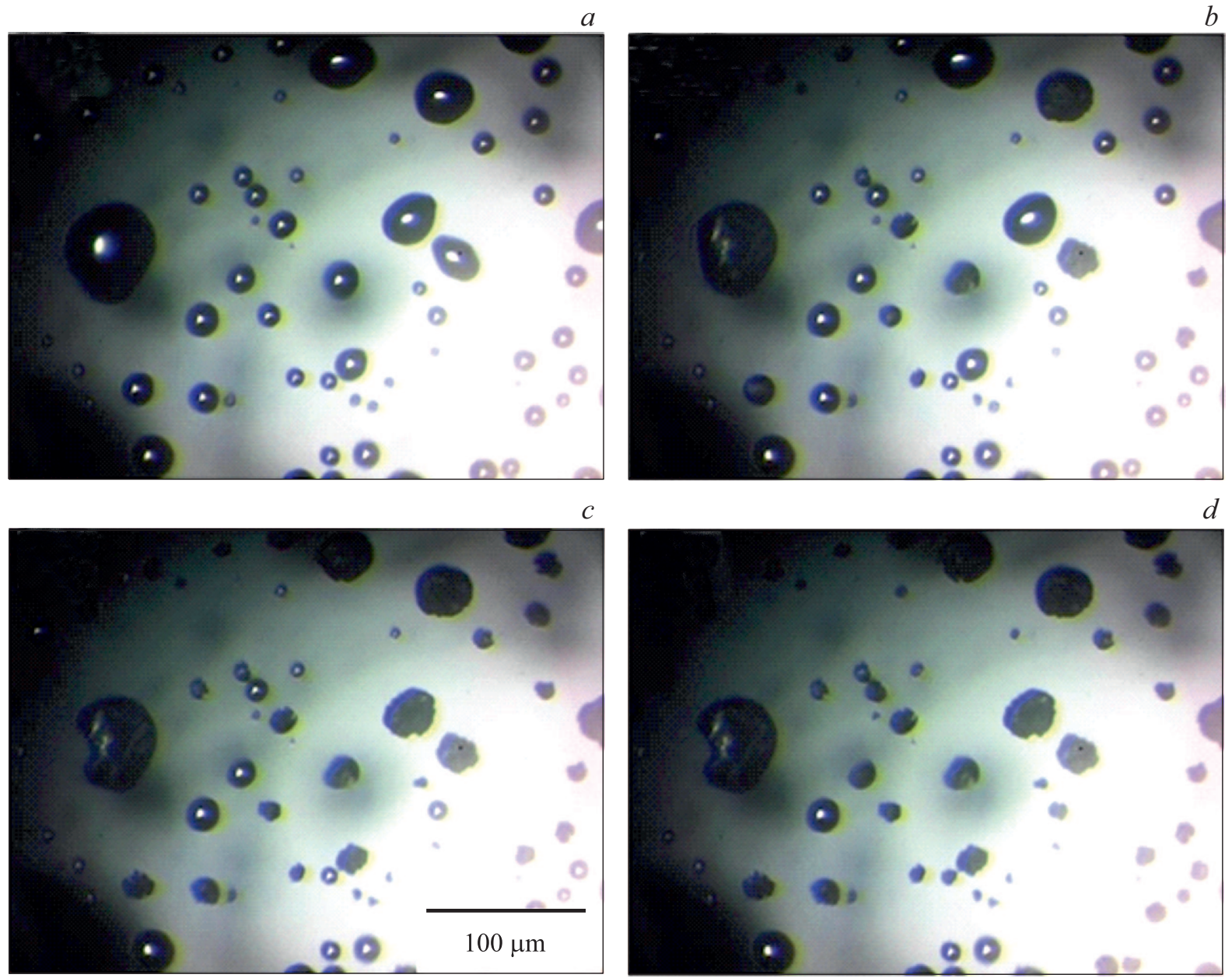

Рис. 2. Последовательность состояний ансамбля капель 50\% раствора уротропина на стекле через: $a-60, b-190, c-200$, $d-205 \mathrm{~s}$ от начала съемки.

Гидрохинон имеет невысокую растворимость $(7.334 \mathrm{~g}$ на $100 \mathrm{ml}$ воды при $25^{\circ} \mathrm{C}$ ), испарение большинства капель раствора происходит в соответствии с оствальдовским созреванием. Диаметр капель при испарении практически не меняется, кристаллообразование начинается по периметру капли с образованием характерных кольцевых структур, что является следствием поверхностной активности. НП демонстрируют отдельные капли микронного размера, кристаллизовавшиеся в последнюю очередь.

Карбамид имеет растворимость $51.8 \mathrm{~g}$ на $100 \mathrm{ml}$ воды при $20^{\circ} \mathrm{C}$. Наблюдение НП несколько затрудняет поверхностная активность вещества, которая проявляется в сохранении диаметра капли при испарении (негидрофобизированная стеклянная подложка) и образовании твердой оболочки, капсулирующей раствор.

Фенол имеет невысокую растворимость в воде $(8 \mathrm{~g}$ на $100 \mathrm{ml}$ при $20^{\circ} \mathrm{C}$ ), обладает поверхностной активностью и летучестью (давление насыщенного пара $\sim 30 \mathrm{~Pa}$ при $20^{\circ} \mathrm{C}$ ). При испарении наблюдается быстрое сокращение объема капель, при этом внутри крупных капель последовательно происходит распад раствора жидкость-жидкость, испарение одной из фаз, образование кристаллов фенола в центральной части капли и испарение окружающего их раствора. Эффект НП не зафиксирован, но в каплях с радиусом до $10-20 \mu \mathrm{m}$ фазового распада жидкость-жидкость не наблюдалось, хотя в них при быстром испарении раствор должен быть сильно пересыщен фенолом.

Резориин как фенол и гидрохинон является представителем ароматических спиртов, хорошо растворим в воде $\left(123 \mathrm{~g}\right.$ на $100 \mathrm{ml}$ при $\left.20^{\circ} \mathrm{C}\right)$. В процессе испарения капли раствора переходили в стабильное состояние, сохраняющееся на протяжении нескольких суток без кристаллизации и изменения размеров. При понижении влажности образовывались кольцевые структуры либо кристаллы, смоченные раствором, на периферии крупных капель.

Приведенные результаты не исчерпывают все органические соединения, для которых наблюдалось НП. В частности, эффект удалось наблюдать в единичных опытах с щавелевой и винной кислотами, которые имеют невысокую поверхностную активность [22]. 

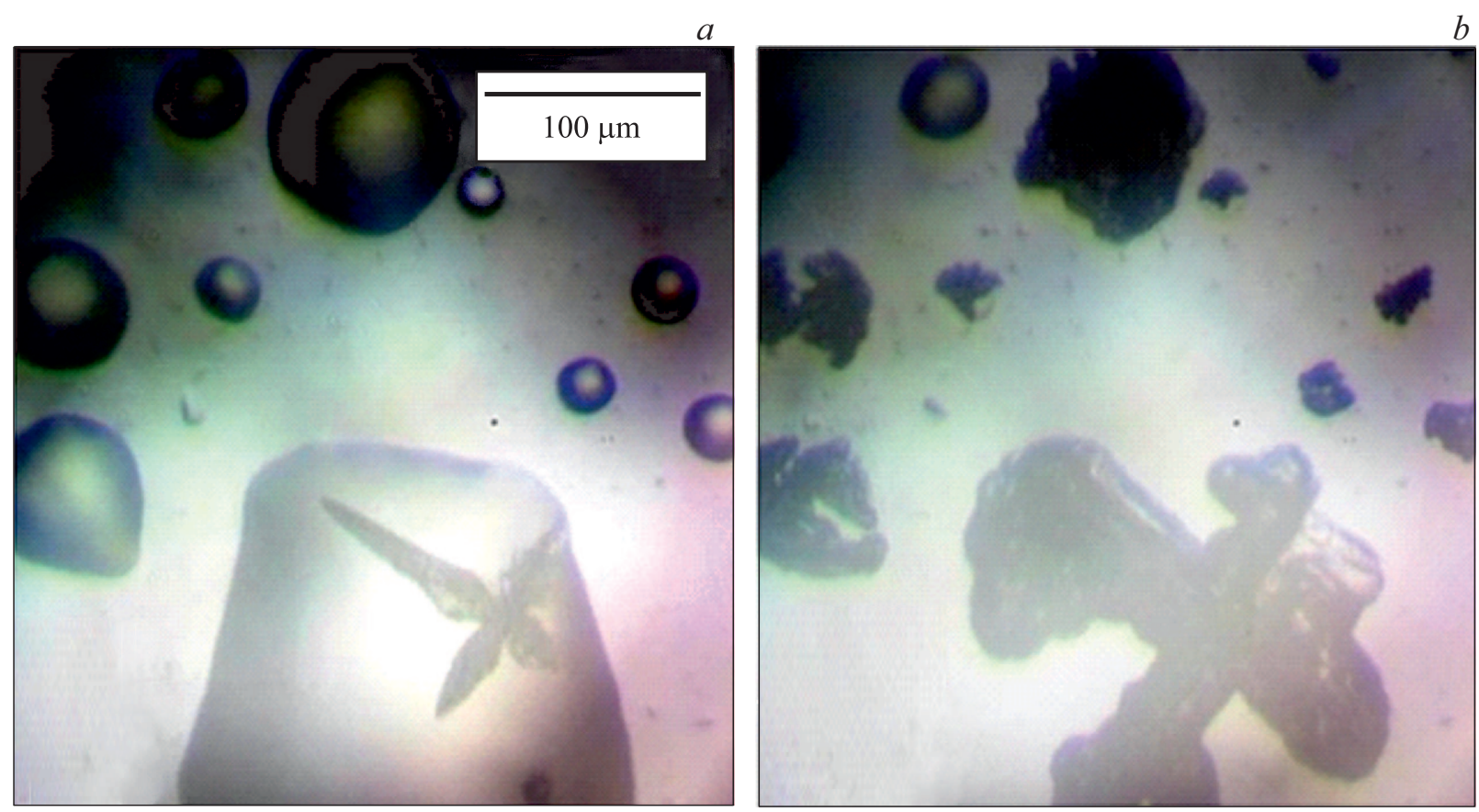

Рис. 3. Образование кристаллов в каплях раствора уротропина в этиловом спирте $(2.5 \%$ в $96 \%$ спирте $)$ на стеклянной подложке через: $a-95$ и $b-120$ s от начала съемки.

\section{Термодинамическая интерпретация и обсуждение результатов}

Эффект оствальдовского созревания описан более века назад и воспроизведен для дисперсных систем разной природы. Процесс заключается в переносе летучего или растворенного компонента от мелких частиц к крупным. В случае ансамбля испаряющихся капель он сводится к увеличению скорости испарения мелких капель. Предложенная Оствальдом термодинамическая интерпретация [23] основана на зависимости давления насыщенного пара от кривизны поверхности, которая для фазовых превращений жидкость-пар описывается уравнением Кельвина, а для системы раствор-кристалл - уравнениями Оствальда-Фрейндлиха. Эти уравнения описывают зависимость давления насыщенного пара летучего компонента $P(r)$ около капли или концентрацию насыщенного раствора $x(L)$ от радиуса капли $r$ либо размера кристалла $L$ соответственно

$$
\begin{aligned}
& P(r)=P_{0} \exp \left(\frac{2 \sigma V_{0}}{r R T}\right), \\
& x(L)=x_{\text {sat }} \exp \left(\frac{4 \sigma V_{0}}{L R T}\right) .
\end{aligned}
$$

Здесь $P_{0}$ - давление насыщенного пара чистого летучего компонента над плоской поверхностью, $x_{\text {sat }}-$ концентрация насыщенного раствора нелетучего компонента, $V_{0}$ - молярный объем, $\sigma$ - удельная поверхностная энергия.
Согласно (1a), (1б), чем меньше радиус, тем выше давление пара около капли, поэтому в ансамбле капель разного размера возникает градиент давления или концентрации, который вызывает массоперенос от мелких капель к крупным и во внешнюю среду. По этой же причине в открытой системе мелкие капли испаряются с большей скоростью. Если смесь содержит нелетучие компоненты, то испарение сопровождается уменьшением радиуса капли и изменением концентрации компонентов. При этом давление насыщенного пара над идеальным раствором зависит от концентрации и определяется законом Рауля

$$
P\left(x_{s}\right)=P_{0} x_{s} .
$$

Здесь $x_{s}$ - мольная доля летучего растворителя (воды). При испарении уменьшается радиус капли, растет концентрация нелетучего компонента $x(r)$ и уменьшается мольная доля летучего компонента $x_{s}(r)=1-x(r)$. Согласно соотношению

$$
P\left(r, x_{s}\right)=P_{0}(1-x(r)) \exp \left(\frac{2 \sigma V_{0}}{r R T}\right)
$$

объединяющему уравнение Кельвина (1a), (1b) с законом Рауля (2), здесь может реализоваться ситуация, когда давление насыщенного пара в окрестности больших капель выше, чем около мелких. Это связано с тем, что величина $x(r)$ определяется количеством нелетучего компонента в каплях. В результате возможен массоперенос летучего компонента от крупных капель раствора к мелким. 
В общем случае поверхностное натяжение раствора зависит от концентрации растворенного вещества $\sigma=\sigma\left(x_{s}\right)$, что также влияет на особенности эволюции дисперсных систем. Органические вещества чаще всего являются поверхностно активными (ПАВ). Для ПАВ $\frac{d \sigma}{d x_{s}}<0$, поэтому рост концентрации сопровождается симбатным уменьшением сомножителей в соотношении (3) и дополнительным понижением давления над каплей. Неорганические вещества, для которых в [8-11] наблюдалось НП, относятся к слабым поверхностно инактивным веществам (ПИВ) $\frac{d \sigma}{d x_{s}}>0$. Для ПИВ с ростом концентрации раствора экспоненциальный множитель в (1a), (1b) и давление пара возрастают. Таким образом, процессы массопереноса между каплями для растворов ПАВ и ПИВ несколько отличаются. У ПАВ массоперенос между каплями равного радиуса однозначно направлен в сторону капли с более высокой концентрацией, тогда как у ПИВ в тех же условиях массоперенос может быть направлен и в сторону капли с меньшей концентрацией.

Описанная выше простая модель пренебрегает неидеальностью растворов органических веществ и не учитывает тепловые эффекты, меняющие температуру испаряющихся или растущих капель. Тем не менее она позволяет оценить условия, при которых может наблюдаться НП ансамбля капель.

Результаты наблюдений позволяют утверждать, что неоствальдовское поведение характерно и для растворов органических соединений, что подтверждает термодинамическую природу эффекта. Кроме того, эксперимент с водно-органическими смесями позволил выявить важную роль поверхностных свойств компонентов раствора. Для органических веществ, обычно проявляющих свойства ПАВ, рост концентрации растворенного компонента приводит к уменьшению поверхностного натяжения, краевого угла и увеличению радиуса кривизны сидячих капель. Это, согласно (3), способствует понижению давления насыщенного пара и над сидячими, и над сферическими каплями. Большинство неорганических солей являются слабыми ПИВ, для них рост концентрации раствора сопровождается увеличением поверхностного натяжения и уменьшением радиуса кривизны капель, более высоким давлением пара.

Такие изменения давления пара растворителя в процессе испарения могут определять характер эволюции дисперсной системы. Например, в соответствии с (3) в растворах ПАВ массоперенос между каплями равного радиуса однозначно направлен в сторону капли с более высокой концентрацией. При тех же условиях для раствора ПИВ массоперенос может быть направлен в сторону капли с меньшей концентрацией. Уменьшение краевого угла маскирует процессы созревания и массопереноса в дисперсных системах, образованных на твердой поверхности. Рост концентрации ПАВ приводит к уменьшению краевого угла и высоты сидячих капель, радиус кривизны при этом возрастает. Площадь контакта с подложкой испаряющейся капли растворов ПИВ уменьшается, тогда как площадь контакта для раствора ПАВ может меняться неоднозначно, вплоть до образования островковых пленок (карбамид). Гидрофобные подложки (лавсан, гидрофобизированное стекло) позволяют частично компенсировать эффекты, связанные с поверхностной активностью.

Есть несколько сценариев эволюции ансамбля испаряющихся капель раствора. В растворах с низкой концентрацией нелетучего компонента на первой стадии наблюдается быстрое испарение мелких капель до размера, когда рост концентрации выравнивает давление пара около мелких и крупных капель $P\left(r_{1}, x_{1}\right)=P\left(r_{2}, x_{2}\right)$, и в соответствии с (3) если $r_{1}>r_{2}$, то $x_{1}<x_{2}$. На этой стадии поведение дисперсной системы соответствует оствальдовскому - мелкие капли испаряются быстрее. После этого наблюдается НП - большие капли испаряются быстрее при практически постоянном размере мелких. Испарение продолжается до выравнивания давления пара в окрестности капель с внешним давлением $P\left(r, x_{s}\right)=P_{\text {ex. }}$. Если насыщение не достигается, эволюция дисперсной системы прекращается при $P\left(r_{1}, x_{1}\right)=P\left(r_{2}, s_{2}\right)=P_{\mathrm{ex}}$ (водный раствор резорцина $)$. Если достигается пересыщение, то происходит зарождение и рост кристаллов. При этом НП проявляется в том, что в первую очередь кристаллизация начинается в крупных каплях, где при равном давлении пара пересышение меньшее (если $r_{1}>r_{2}$, то $x_{1}<x_{2}$ ). Для растворов с высокой концентрацией нелетучего компонента визуальное наблюдение затрудняется тем, что кристаллизация в каплях может начинаться до или вовремя образования контактной площадки.

Для дисперсных систем, образованных растворами органических веществ, также характерны осциллирующие фазовые превращения, обнаруженные для неорганических солей $[10,11]$. Непродолжительные осцилляции размера капель наблюдались в опытах с водно-спиртовым раствором уротропина, водными растворами глицина и карбамида.

\section{Заключение}

Экспериментально воспроизведено неоствальдовское поведение дисперсных систем, образованных растворами органических соединений, которое ранее было описано только для водных растворов ряда неорганических солей. Продемонстрировано, что чем меньше объем дисперсной частицы, тем выше ее устойчивость при испарении и фазовых превращениях. Эффект воспроизведен для веществ, представляющих разные классы органических соединений. Это подтверждает его термодинамическую природу, расширяя представление об оствальдовском созревании в многокомпонентных дисперсных системах.

Микроскопическое наблюдение НП для водно-органических растворов некоторых органических соединений может быть затруднено их высокой поверхностной 
активностью. В отдельных случаях эту проблему позволяет обойти использование гидрофобных подложек.

Эксперимент позволяет утверждать, что пересыщение, при котором начинается кристаллизация, возрастает с уменьшением размеров капли. Повышение растворимости органических и биоорганических веществ при малых объемах раствора является следствием размерных эффектов, представляющим интерес для органического синтеза, фармацевтики. Для спрей-технологий важным следствием описанных эффектов являются закономерности формирования устойчивых бимодальных распределений капель по размерам [24].

\section{Финансирование работы}

Работа выполнена в рамках государственного задания ИМХ PAH, а также при поддержке Российского фонда фундаментальных исследований (проект 18-08-01356-а).

\section{Конфликт интересов}

Авторы заявляют, что у них нет конфликта интересов.

\section{Список литературы}

[1] Littringer E.M., Paus R., Mescher A., Schroettner H., Walzel P., Urbanetz N.A. // Powder Technol. 2013. Vol. 239. P. 162. DOI: 10.1016/j.powtec.2013.01.065

[2] Тарасевич Ю.Ю., Православнова Д.М. // ЖТФ. 2007. Т. 77. Вып. 2. C. 17-21. DOI: 10.1134/S106378420702003X

[3] Яхно Т.А., Казаков В.В., Санина О.А., Санин А.Г., Яхно В.Г. // ЖТФ. 2010. Т. 80. Вып. 7. С. 17-23. DOI: $10.1134 / \mathrm{S} 1063784210070030$

[4] Droplet Wetting and Evaporation From Pure to Complex Fluids / Ed. Brutin D. Amsterdam: Academic Press, 2015. P. 435 .

[5] Ostafin A., Landfester $K$. Nanoreactor engineering for life sciences and medicine. Boston: Artech House, 2009.

[6] Пенязьков О.Г., Саверченко В.И., Фисенко С.П. // Письма в ЖТФ. 2013. Т. 39. Вып. 3. С. 56. DOI: $10.1134 / \mathrm{S} 1063785013020132$

[7] Strotos G., Gavaises M., Theodorakakos A., Bergeles G. // Fuel. 2011. Vol. 90. N 4. P. 1492. DOI: $10.1016 /$ j.fuel.2011.01.017

[8] Федосеев В.Б., Федосеева Е.Н. // Письма в ЖЭТФ. 2013. T. 97. Вып. 7. C. 473. DOI: $10.1134 / \mathrm{S} 0021364013070059$

[9] Титаева Е.К., Федосеев В.Б. // Кристаллография. 2014. T. 59. № 3. C. 484. DOI: $10.1134 / \mathrm{S} 1063774514030195$

[10] Федосеев В.Б., Максимов М.В. // Письма в ЖЭТФ. 2015. T. 101. Вып. 6. C. 424. DOI: 10.1134/S0021364015060053

[11] Федосеев В.Б. // Нелинейная динамика. 2017. Т. 13. № 2. C. 195 . DOI: $10.20537 / \mathrm{nd} 1702004$

[12] Burlakov V.M., Bootharaju M.S., Besong T.M.D., Bakr O.M., Goriely A. arXiv:1412.6280v2 [physics.chem-ph]. 2014. P. 11.

[13] Sugimoto I. // J. Soc. Photogr. Sci. Technol. Jpn. 1983. Vol. 46. N 4. P. 306.

[14] Leizerson I., Lipson S.G., Lyushnin A.V. // Nature. 2003. Vol. 422. N 6930. P. 395. DOI: $10.1038 / 422395 b$

[15] Heinig K., Schmidt B., Strobel M., Bernas H. // MRS Proceedings. 2000. Vol. 650. R9.6/O14.6.
DOI: 10.1557/PROC-650-R9.6/O14.6

[16] Singh A., Kumari R., Kumar V., Krishnia L., Naqvi Z., Panwar A.K., Bhatta U.M., Ghosh A., Satyam P.V., Tyagi P.K. // Appl. Surf. Sci. 2016. Vol. 360. December. P. 1003. DOI: 10.1016/j.apusc.2015.11.110

[17] Rizza G.C., Strobel M., Heinig K.H., Bernas H. // Nucl. Instruments Methods Phys. Res. B. 2001. Vol. 178. November. P. 78. DOI: $10.1016 / \mathrm{S} 0168-583 \mathrm{X}(01) 00496-7$

[18] Задымова Н.М., Аршакян Г.А. // Коллоидный журнал. 2014. T. 76. № 1. C. 28. DOI: $10.1134 / \mathrm{S} 1061933$ X14010165

[19] Lucas S., Moskovkin P. // Thin Solid Films. 2010. Vol. 518. N 18. P. 5355. DOI: 10.1016/j.tsf.2010.04.064

[20] Федосеев В.Б., Шишулин А.В., Титаева Е.К., Федосеева Е.Н. // ФТТ. 2016. Т. 58. Вып. 10. С. 2020. DOI: $10.1134 / \mathrm{S} 1063783416100152$

[21] Рагузина Ю.С., Федосеева Е.Н. // XI Всерос. шк.-конф. мол. ученых. Теоретическая и экспериментальная химия жидкофазных систем. (Крестовские чтения). Иваново, 2017. C. 163.

[22] Лободина Е.С., Скудаев В.И. // Вестник Пермского нац. исслед. политех. ун-та. Химическая технология и биотехнология. 2009. Т. 8. С. 239.

[23] Ostwald W. // Zeitschrift für Phys. Chemie. 1897. Vol. 22. N 2. P. 289.

[24] Федосеев В.Б., Федосеева Е.Н. // ИФЖ. 2019. Т. 92. № 5. C. 2229. DOI: 10.1007/s10891-019-02033-2 